\title{
Intervensi Pendidikan Kesehatan terhadap Perubahan Pengetahuan mengenai Kejadian Dermatitis dan Pencegahannya di Desa Pantai Cermin Kanan Kecamatan Pantai Cermin Kabupaten Serdang Bedagai
}

\author{
Annisa Febriana Siregar ${ }^{1, *}$, Anggi Isnani Parinduri ${ }^{2}$

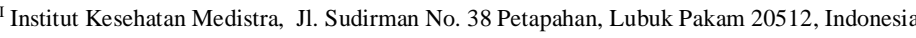 \\ ${ }^{2}$ Institut Kesehatan Medistra, Jl. Sudirman No. 38 Petapahan, Lubuk Pakam 20512, Indonesia \\ ${ }^{1}$ Email: nsafbrn@gmail.com*; ${ }^{2}$ Email : anggisnani@gmail.com \\ * corresponding author
}

ARTICLE INFO

Keywords

Knowledge

Fisherman

Dermatitis

\section{ABSTRACT}

Fishermen are prone to skin diseases due to the influence of sea water because the concentration of salt draws water from the skin. Sea water is a cause of dermatitis with primary stimulation properties. Recent research results reveal that fishermen have a high potential for disease, work accidents, and mental health and other physical-related illnesses. The purpose of this study was to determine the effect of leaflet and extension media on changes in knowledge about the incidence of dermatitis between before and after counseling to fishermen in Pantai Cermin Kanan Village, Pantai District in 2020. The design of this research is a non-equivalent control group design study. Nonequivalent Control Group Design is a form of Quasi-Experimental. The research population was 50 fishermen in Pantai Cermin Kanan District. The data collection method uses primary data, namely data that is directly obtained from respondents using a questionnaire in the form of a statement or written question. The data analysis used in this study consisted of univariate and bivariate analyzes. This analysis uses descriptive statistics to describe the frequency distribution of the independent and dependent variables which are presented in tabular form. The bivariate analysis used in this study was the Paired Sample Ttest. There is a difference in the knowledge of fishermen in Pantai Cermin Kanan Village regarding the use of good PPE between before and after a health education intervention regarding the potential dangers of dermatitis and its prevention.

\section{Pendahuluan}

Produktivitas kerja yang optimal akan terwujud bilamana perhatian tentang upaya perlindungan tenaga kerja oleh berbagai aspek dapat mendukung tercapainya derajat kesehatan yang maksimal. Salah satu faktor penting yang harus diperhatikan terkait produktivitas kerja adalah kesehatan kerja bagi tenaga kerja, yang bertujuan untuk menciptakan tenaga kerja yang sehat, produktif sera mencegah penyakit akibat kerja (PAK).

Penyakit akibat kerja merupakan penyakit yang berhubungan dengan pekerjaan dan kecelakaan kerja yang dapat menyebabkan kecacatan bahkan kematian. Dermatitis kontak akibat kerja merupakan salah satu penyakit akibat kerja, yang dapat mengurangi kenyamanan dalam melakukan pekerjaan dan akhirnya akan mempengaruhi produktivitas kerja secara keseluruhan. Dermatitis kontak merupakan peradangan pada kulit disebabkan oleh suatu bahan yang kontak dengan kulit. Dermatitis kontak akibat kerja sering terjadi pada pekerja informal yang umumnya kurang memperhatikan sanitasi dan perlindungan bagi kesehatan dirinya [1].

Salah satu sektor informal terbesar di Indonesia adalah maritim yang semakin lama kian berkembang. Nelayan merupakan istilah bagi orang-orang yang sehari-harinya bekerja menangkap 
ikan atau biota lainnya yang hidup di dasar, kolam maupun permukaan perairan. Perairan yang menjadi daerah aktivitas nelayan ini dapat merupakan perairan tawar, payau maupun laut. Nelayan rentan terhadap penyakit kulit akibat pengaruh air laut karena kepekatannya oleh garam menarik air dari kulit. Air laut merupakan penyebab dermatitis dengan sifat rangsangan primer. Hasil penelitan terbaru mengungkapkan bahwa nelayan mempunyai potensi tinggi untuk terkena penyakit, kecelakaan kerja, dan kesehatan mental dan penyakit yang berhubungan fisik lainnya [2].

Prevalensi dermatitis kontak di Indonesia sangat bervariasi. Pada tahun 2007, sekitar 90\% penyakit kulit akibat kerja merupakan dermatitis kontak, baik iritan maupun alergik. Pada studi epidemiologi, Indonesia memperlihatkan bahwa 97\% dari 389 kasus adalah dermatitis kontak dimana 66,3\% di antaranya adalah dermatitis kontak iritan dan 33,7\% adalah dermatitis kontak alergi[3]. Pekerja seperti nelayan, yang mempunyai riwayat penyakit kulit akan lebih mudah mengalami dermatitis karena fungsi perlindungan kulit telah berkurang dikarekan oleh penyakit kulit yang diderita sebelumnya. Sebuah penelitian menyatakan bahwa riwayat penyakit atau alergi adalah faktor dominan yang berhubungan dengan penyakit kulit (OR: 6,74) [4].

Pendidikan kesehatan adalah suatu kegiatan atau usaha menyampaikan pesan kesehatan kepada masyarakat, kelompok atau individu [5]. Dengan harapan bahwa dengan adanya pesan tersebut, maka masyarakat, kelompok atau individu dapat memperoleh pengetahuan tentang kesehatan yang lebih baik. Dan pada akhirnya pengetahuan tersebut diharapkan dapat berpengaruh terhadap perilaku. Dimana tujuan dari pendidikan kesehatan ini adalah agar masyarakat, kelompok atau individu dapat berperilaku sesuai dengan nilai-nilai kesehatan. Salah satu bentuk media dalam pendidikan kesehatan ialah dengan pemberian leaflet.

Melihat permasalahan diatas, maka penting dilakukan penelitian mengenai intervensi pendidikan kesehatan terhadap perubahan pengetahuan mengenai kejadian dermatitis dan pencegahannya di Desa Pantai Cermin Kanan Kecamatan Pantai Cermin Kanan Kabupaten Serdang Bedagai Tahun 2020. Hasil penelitian ini dapat menjadi dasar untuk penelitian lebih lanjut untuk mendapatkan pengetahuan yang lebih luas dalam rangka menyusun perencanaan dan program penanggulangan terhadap nelayan yang terkena dermatitis.

\section{Metode}

Rancangan penelitian ini adalah suatu studi Non-equivalent Control Group Design. Nonequivalent Control Group Design adalah salah satu bentuk Quasi-Experimental Design dengan kelompok nelayan yang kemudian diberikan kuisioner pre-test untuk mengetahui pengetahuan awal nelayan tersebut dan yang kedua diberikan penyuluhan dengan media leaflet. Populasi penelitian adalah nelayan yang berada di Kecamatan Pantai Cermin Kanan yang berjumlah 50 orang.

Metode pengumpulan data menggunakan data primer yaitu data yang sercara langsung diperoleh dari responden dengan menggunakan kuesioner dalam bentuk pernyataan atau pertanyaan tertulis. Analisa data yang digunakan dalam penelitian ini terdiri dari analisa univariat dan bivariat. Analisis ini menggunakan statistic deskriptif untuk menggambarkan distribusi frekuensi dari variable bebas dan variable terikat yang disajikan dalam bentuk tabel. Analisi bivariat yang digunakan dalam penelitian ini adalah uji Paired Sample T-test.

\section{Hasil dan Diskusi}

\section{A. Analisis Univariat}

Tabel 1. Distribusi Frekuensi Karakteristik Responden Berdasarkan Umur

\begin{tabular}{|c|c|c|c|}
\hline Kategori & Umur & $\mathbf{F}$ & $\%$ \\
\hline 1 & $<30$ Tahun & 15 & 30,0 \\
\hline 2 & $>30$ Tahun & 35 & 70,0 \\
\hline \multicolumn{2}{|c|}{ Jumlah } & $\mathbf{5 0}$ & 100 \\
\hline
\end{tabular}


Berdasarkan tabel 1 dapat diketahui bahwa umur responden terbanyak adalah umur $>30$ tahun yaitu sebanyak 35 responden $(70,0 \%)$ sedangkan umur paling sedikit adalah $<30$ tahun sebanyak 15 responden.

Tabel 2. Distribusi Frekuensi Karakteristik Responden Berdasarkan Pendidikan Terakhir

\begin{tabular}{clcc}
\hline Kategori & Pendidikan & F & \% \\
\hline $\mathbf{1}$ & Tidak sekolah & 5 & $\mathbf{1 0 , 0}$ \\
$\mathbf{2}$ & SD & 14 & $\mathbf{2 8 , 0}$ \\
$\mathbf{3}$ & SMP & 15 & $\mathbf{3 0 , 0}$ \\
$\mathbf{4}$ & SMA & 16 & $\mathbf{3 2 , 0}$ \\
\hline & Jumlah & $\mathbf{5 0}$ & $\mathbf{1 0 0}$ \\
\hline
\end{tabular}

Berdasarkan tabel 2 dapat diketahui bahwa pendidikan terakhir responden terbanyak adalah SMA yaitu sebanyak 16 responden $(32,0 \%)$ sedangkan pendidikan terakhir paling sedikit adalah tidak sekolah yaitu sebanyak 5 responden $(10,0 \%)$.

Tabel 3. Distribusi Frekuensi Karakteristik Responden Berdasarkan Lama Bekerja

\begin{tabular}{clcc}
\hline Kategori & Lama Bekerja & F & \% \\
\hline $\mathbf{1}$ & Baru $>3$ tahun & 21 & $\mathbf{4 2 , 0}$ \\
$\mathbf{2}$ & Lama $<3$ tahun & 29 & $\mathbf{5 8 , 0}$ \\
\hline & Jumlah & $\mathbf{5 0}$ & $\mathbf{1 0 0}$ \\
\hline
\end{tabular}

Berdasarkan tabel 3 dapat diketahui bahwa lama bekerja responden terbanyak adalah $<3$ tahun yaitu sebanyak 29 orang $(58,0 \%)$ sedangkan lama bekerja responden yang paling sedikit yaitu sebanyak $>3$ tahun dengan jumlah responden 21 responden $(42,0 \%)$.

Tabel 4. Distribusi Frekuensi Karakteristik Responden Berdasarkan Penggunaan APD

\begin{tabular}{clcc}
\hline Kategori & Penggunaan APD & F & \% \\
\hline $\mathbf{1}$ & Menggunakan & 15 & $\mathbf{3 0 , 0}$ \\
$\mathbf{2}$ & Tidak menggunakan & 35 & $\mathbf{7 0 , 0}$ \\
\hline & Jumlah & $\mathbf{5 0}$ & $\mathbf{1 0 0}$ \\
\hline
\end{tabular}

Berdasarkan tabel 4 diketahui bahwa penggunaan APD terbanyak 35 responden $(70,0 \%)$ dan responden yang tidak menggunakan 15 orang $(30,0 \%)$.

Tabel 5. Distribusi Frekuensi Karakteristik Responden Berdasarkan Kejadian Dermatitis

\begin{tabular}{|c|c|c|c|}
\hline Kategori & Kejadian Dermatitis & $\mathbf{F}$ & $\%$ \\
\hline 1 & Ada & 27 & 54,0 \\
\hline 2 & Tidak ada & 23 & 46,0 \\
\hline & Jumlah & 50 & 100 \\
\hline
\end{tabular}

Berdasarkan tabel 5 diketahui bahwa kejadian dermatitis terbanyak 27 responden (54,0\%) dan yang tidak mengalami dermatitis sebanyak 23 responden (46\%). 


\section{Analisis Bivariat}

Tabel 6. Hasil uji Pengaruh Intervensi Penyuluhan menggunakan Media Leaflet terhadap Perubahan Pengetahuan mengenai kejadian Dermatitis dan Pencegahannya di Desa Pantai Cermin Kanan

\begin{tabular}{llcc}
\hline \multicolumn{1}{c}{ Pengetahuan } & Mean & SD & P Value \\
\hline Pre-test & 5,02 & 1.186 & 0,032 \\
Post-test & 8,06 & 1,018 & \\
\hline
\end{tabular}

Berdasarkan tabel di atas diketahui bahwa terjadi perubahan nilai rata-rata pengetahuan sebelum intervensi (Pre-test) dengan sesudah intervensi (post-test) dilakukan yaitu 5,02 rnenjadi 8,06. Hal ini berarti tingkat pengetahuan setelah dilakukan intervensi mengalami peningkatan. Hasil uji $\mathrm{T}$ dapat disimpulkan bahwa terdapat pengaruh intervensi pendidikan kesehatan menggunakan media leaflet terhadap perubahan pengetahuan nelayan dengan nilai $p=0,032$.

Penggunaan media leaflet dapat dibawa dengan mudah oleh nelayan dan dapat dibaca kapan saja jika dalam keadaan santai ketika nelayan tersebut sedang tidak berlayar atau sedang istirahat dari pekerjaanya. Pada penelitian ini tingkat pendidikan terbanyak nelayan ialah SMA sehingga tidak ada nelayan yang buta huruf dan memudahkan nelayan untuk membaca dan memahami isi atau pesan yang disampaikan dalam media leaflet tersebut. Kualitas gambar dan kualitas kertas media leaflet mendukung untuk meningkatkan pengetahuan sehingga nelayan yang membaca leaflet tersebut dapat memahami dengan mudah.

\section{Kesimpulan}

1. Terdapat perbedaan pengetahuan nelayan di Desa Pantai Cermin Kanan mengenai penggunaan APD yang baik antara sebelum dan sesudah dilakukan intervensi pendidikan kesehatan mengenai potensi bahaya dermatitis dan pencegahannya.

2. Terdapat hubungan antara pendidikan kesehatan menggunakan media leafket dengan perubahan pengetahuan penyuluhan menggunakan media leaflet mengenai potensi bahaya dermatitis dan pencegahannya pada nelayan.

\section{Saran}

1. Pemberian pendidikan kesehatan pada nelayan di Desa Pantai Cermin Kanan untuk memberikan informasi-informasi pencegahan mengenai dermatitis kontak sebaiknya sering dilakukan untuk menambah wawasan atau pengetahuan nelayan tersebut.

2. Bentuk pendidikan kesehatan tidak hanya dalam bentuk penyuluhan dan pemberian leaflet tetapi dapat diberikan dalam bentuk media lainnya seperti poster, brosur atau spanduk, agar nelayan lebih menjaga kesehatan dan keselamatan dirinya sendiri.

3. Untuk mendukung program pencegahan penyakit dermatitis, sebaiknya instansi terkait atau peneliti selanjutnya dapat memberikan alat pelindung diri (APD) seperti sarung tangan dan sepatu boots untuk nelayan.

\section{Referensi}

[1] Adhi Djuanda, dkk. (2011). Ilmu Penyakit Kulit dan Kelamin. Edisi 6. Jakarta: Fakultas

Kedokteran Universitas Indonesia. p. 3-4, 7-8.

[2] Cahyawati, I.N. (2011). Faktor yang berhubungan dengan Kejadian Dermatitis Pada Nelayan.

Semarang. UNNES- Jurnal Kesehatan Masyarakat. 
[3] Fatmawati, H., (2013). Perubahan Pengetahuan tentang Potensi Bahaya Larutan Penggumpal dan Pencegahan Dermatitis dengan Intervensi Penyuluhan antara Media Lembar Balik dengan Media Leaflet pada Pekerja Pabrik Tahu di Kecamatan Ciputat dan Ciputat Timur. Skripsi Kesehatan

[4] Fitriani, A., (2013). Pengaruh Intervensi Penyuluhan menggunakan Media Leaflet terhadap Perubahan Pengetahuan mengenai Potensi Bahaya Dermatitis Kontak dan Pencegahannya pada Pekerja Cleaning Service UIN Syarif Hidayatullah. Jakarta. Skripsi

[5] Notoatmojo, S. (2010). Konsep perilaku kesehatan. Promosi Kesehatan, Teori Dan Aplikasi. 